\title{
Influence of technological cracks of peeled vener on the shear strength of ultralam bars
}

\author{
Stefania Mironova ${ }^{1, *}$ \\ ${ }^{1}$ Saint Petersburg State University of Architecture and Civil Engineering, 4 Vtoraya \\ Krasnoarmeiskaya, 190005, Saint Petersburg, Russia
}

\begin{abstract}
The aim of the research is to study the shear strength of laminated veneer lumber (LVL) when working on shear in four different planes. To determine the influence of the presence of technological cracks formed in the peeling process, an experiment was carried out for which four types of samples were used. The load was applied parallel and perpendicular to the glue line and the direction of the peeled veneer fibers. As tests have shown, the technological weakening of peeled veneer reduces the strength properties of a multilayer glued veneer bar, especially for shear along the glue lines and perpendicular to the direction of the peeled veneer fibers, where the maximum number of microcracks is located. The analysis of these microcracks is carried out and their widths are determined. The width of the studied cracks was from 152 to $94 \mu \mathrm{m}$. There is no adhesive layer in the microcracks of this building material, which may indicate insufficient wetting of the veneer surface with the adhesive material, or the difficulty of penetration of high-molecular phenolformaldehyde glue into the cavity of microcracks.
\end{abstract}

\section{Introduction}

New types of laminated wood construction materials contribute to the development of the construction industry. Special attention should be paid to the Ultralam multilayer laminated veneer lumber (or LVL) [1, 2, 3]. In packages of veneer sheets, the characteristics of laminated wood are smoothed out along the axes of the elements in comparison with the variability of the corresponding characteristics in the trunk, due to which the LVL beam has a high strength under horizontal load $[4,5,6]$. Therefore, the supporting elements of the frame are the main application of this material [7].

According to the Talion Terra Plant, which is a branch of the STOD LLC in the city of Torzhok, the volume of annual sales after 2013 is over 100 thousand $\mathrm{m} 3$ with a production capacity of 140 thousand $\mathrm{m} 3$ [8]. 95\% of manufactured products are exported. Not significant amounts of LVL beams are used in the Russian construction industry. In addition to the high price, potential consumers are held back by the novelty of the material. There are not many ready-made objects in the country, where LVL beams are used as a supporting structure, and there is no clear idea of how the material will behave during longterm operation.

\footnotetext{
* Corresponding author: mstefania@mail.ru
} 


\section{Materials and methods}

Plywood and LVL beams made of peeled veneer with a large number of layers and orthogonal alternating veneer laying can be classified as orthogonally anisotropic materials (even more than wood), since the curvature of tree rings does not affect their mechanical properties [9]. It should be remembered that cross grains also appear when peeling veneer; knots and cross grain near them are inevitable. Repairing veneer with elliptical patches does not give a positive effect, since the cross grain near knots is cut at the same time (destruction begins precisely in the repair zone). Multilayer laminated beam made of unidirectional LVL veneer has a lower ultimate strength (in tension) in the direction perpendicular to the layers due to the influence of the binder (adhesive layers between layers) $[10,11]$.

The material for the production of Ultralam beam is a $3.2 \mathrm{~mm}$ thick peeled softwood veneer. The veneer has a structure inherent in the tangential section of a tree trunk. When the tree rings are unrolled during the veneer peeling, longitudinal cracks (Fig. 1) of the radial direction are formed $[12,13,14]$.

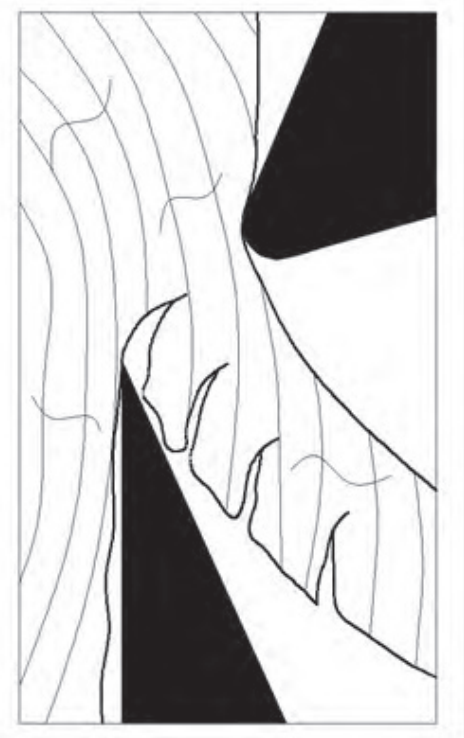

Fig. 1. Cracking when peeling veneer.

The width of their opening depends on the temperature and humidity conditions of log processing and is proportional to the veneer thickness [15]. The combination of these technological interventions in natural material entails the emergence of the weakest link in plywood and LVL: insufficient strength of the glue line, especially when stretched along one of the main axes of symmetry of the sheet plane.

The symmetry of the properties of the LVL beam consisting of a large number of anisotropic layers is determined by the type of anisotropy of individual layers and their mutual arrangement. In order to determine the influence of the presence of cracks formed in the peeling process, an experiment was carried out for which four types of samples shown in figure 2 were used. Shear tests were carried out on a testing machine that meets the requirements of normative and technical documentation (NTD) [16]. In this case, the application of the load was carried out parallel and perpendicular to the adhesive layer and the direction of the peeled veneer grains according to the procedure established in the NTD [17]. 

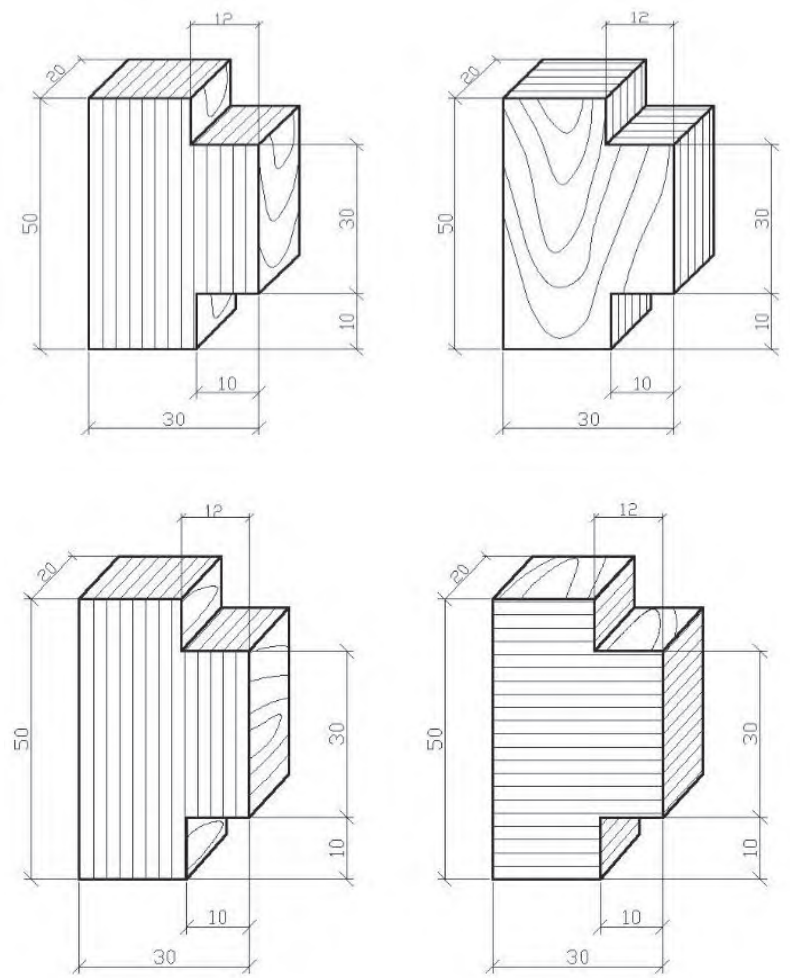

Fig. 2. Samples for shear tests.

\section{Results}

The data of examining samples for shearing parallel to veneer layers and along the gluing surface are shown in figures $3,4,5$ and 6.
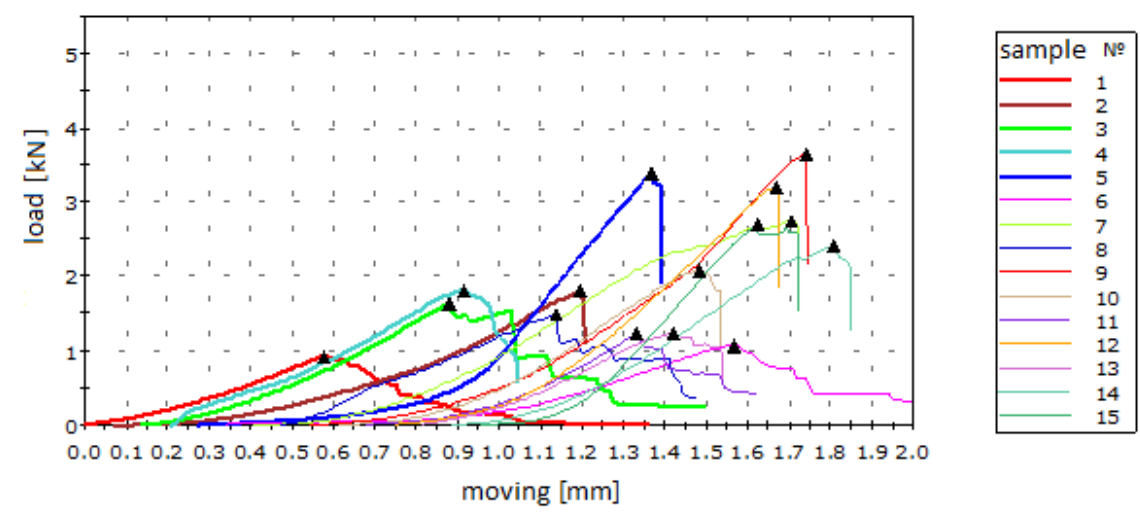

Fig. 3. Determination of the maximum load when shearing LVL parallel to veneer layers. 

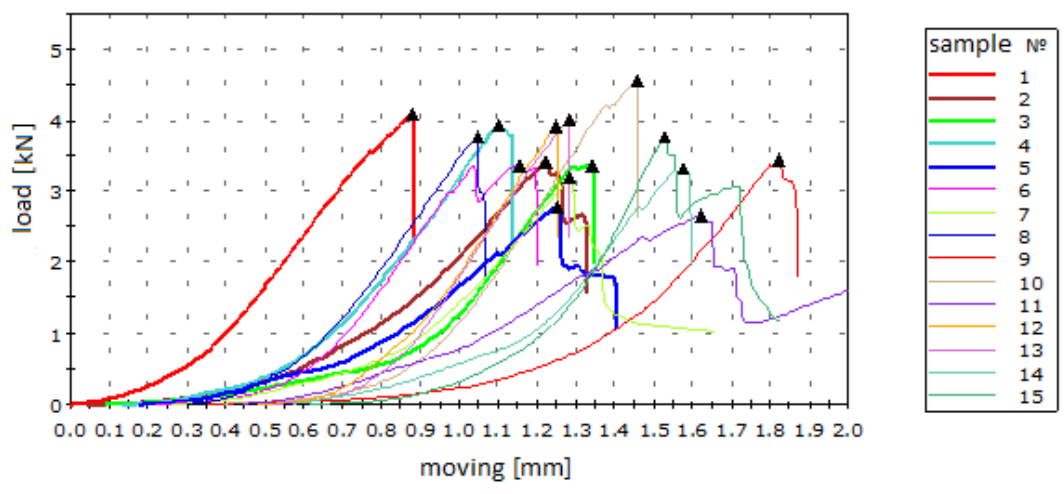

Fig. 4. Determination of the maximum load when shearing LVL along the veneer grain and perpendicular to the adhesive layers.
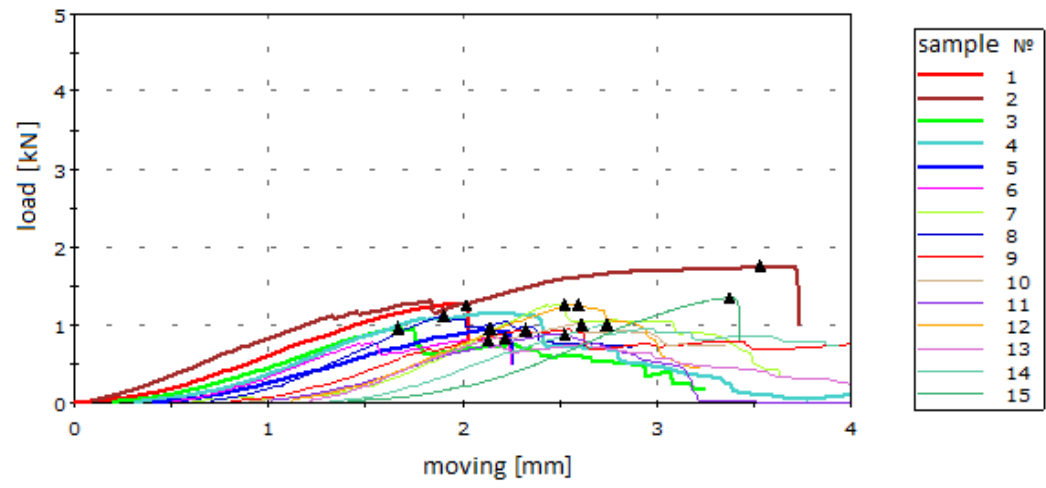

Fig. 5. Determination of the maximum load when shearing LVL along the adhesive layers and perpendicular to the direction of veneer grain.

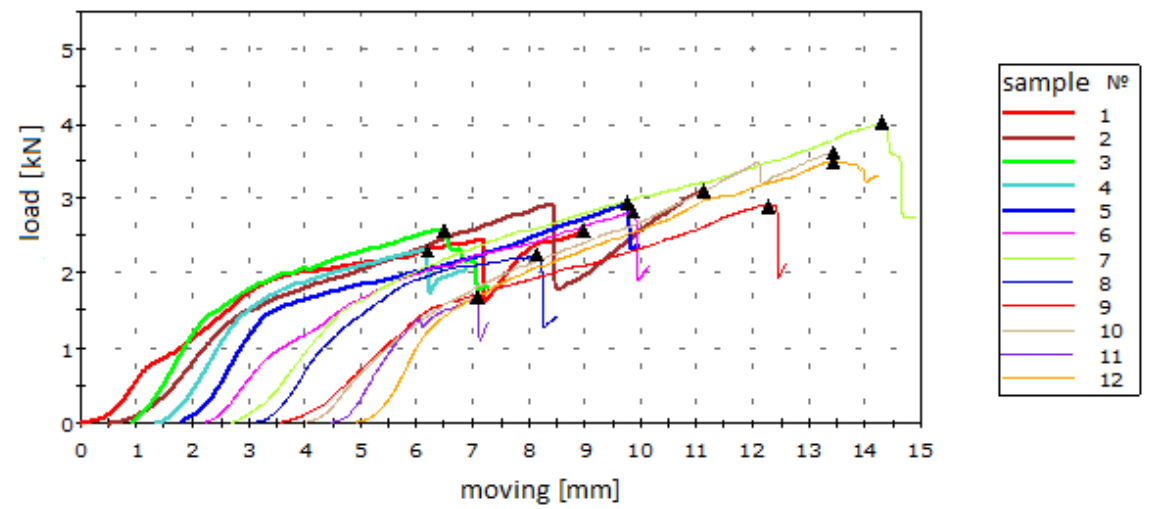

Fig. 6. Determination of the maximum load when shearing LVL perpendicular to the glue lines and perpendicular to the veneer grain. 


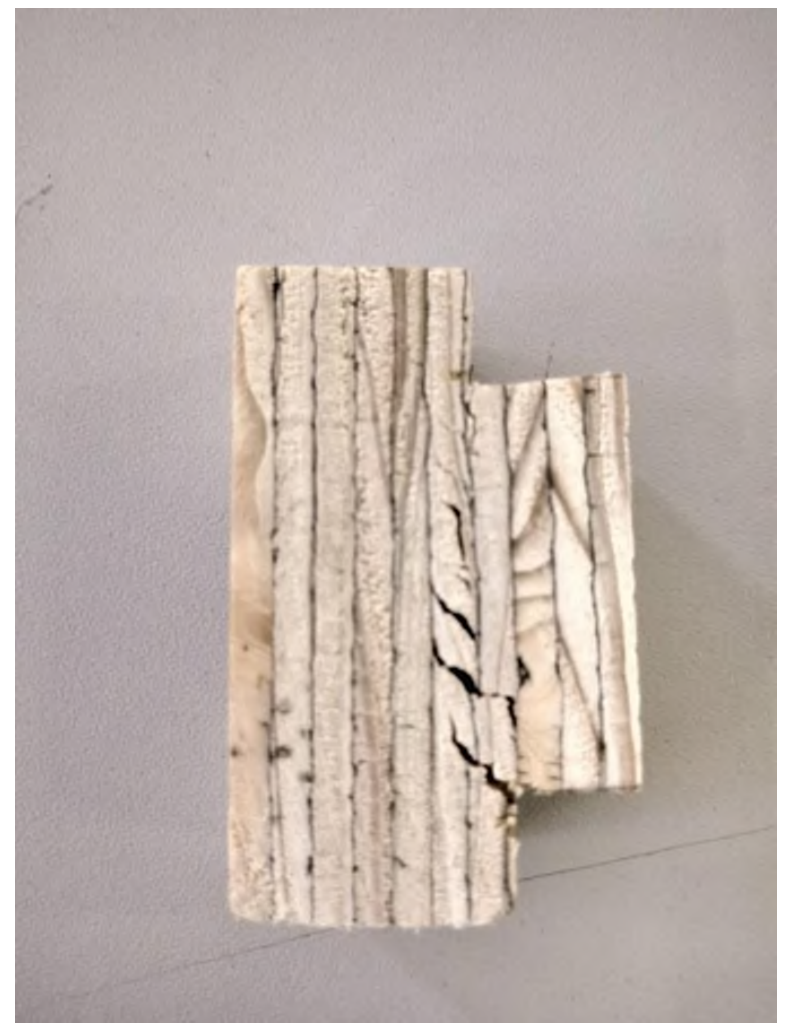

Fig. 7. The nature of destruction when testing the 3rd group of samples.

\section{Discussion}

As one can see from the graphs, the minimum value of strength is observed in samples of the third type, in which shearing occurs along the tangential cross-section, where there is a maximum number of microcracks formed during peeling. In addition, the shear strength in the tangential direction of the wood is lower than in the radial direction. The tensile strength along the tangential cross-section is three times lower than the tensile strength in the second series of samples, where the shearing took place along the grain of the peeled veneer wood. It is clearly seen in figure 7 that the cracks formed during peeling start to open and accelerate the process of destruction of the sample.

Microscopic examination of the test material was carried out using a TESCAN T3M microscope. Figure 8 shows that there are cracks in the building material that are not filled with glue. The maximum width of the detected cracks was 152 and $94 \mu \mathrm{m}$.

Lack of glue may indicate insufficient wettability of the veneer surface with glue. The active interaction of wood veneer and glue ensures good wetting and gives molecular contact between the liquid adhesive and the substrate $[18,19]$. In addition, it should be noted that phenol-formaldehyde resin, which is used in the production of this building material, is of high molecular weight. Resin molecules reach high molecular weight due to chain crosslinking and their elongation [20], which can also affect penetration into microcracks.

Based on the studies carried out, it can be concluded that a new structural material made of $3.2 \mathrm{~mm}$ thick peeled veneer requires careful and comprehensive study. 


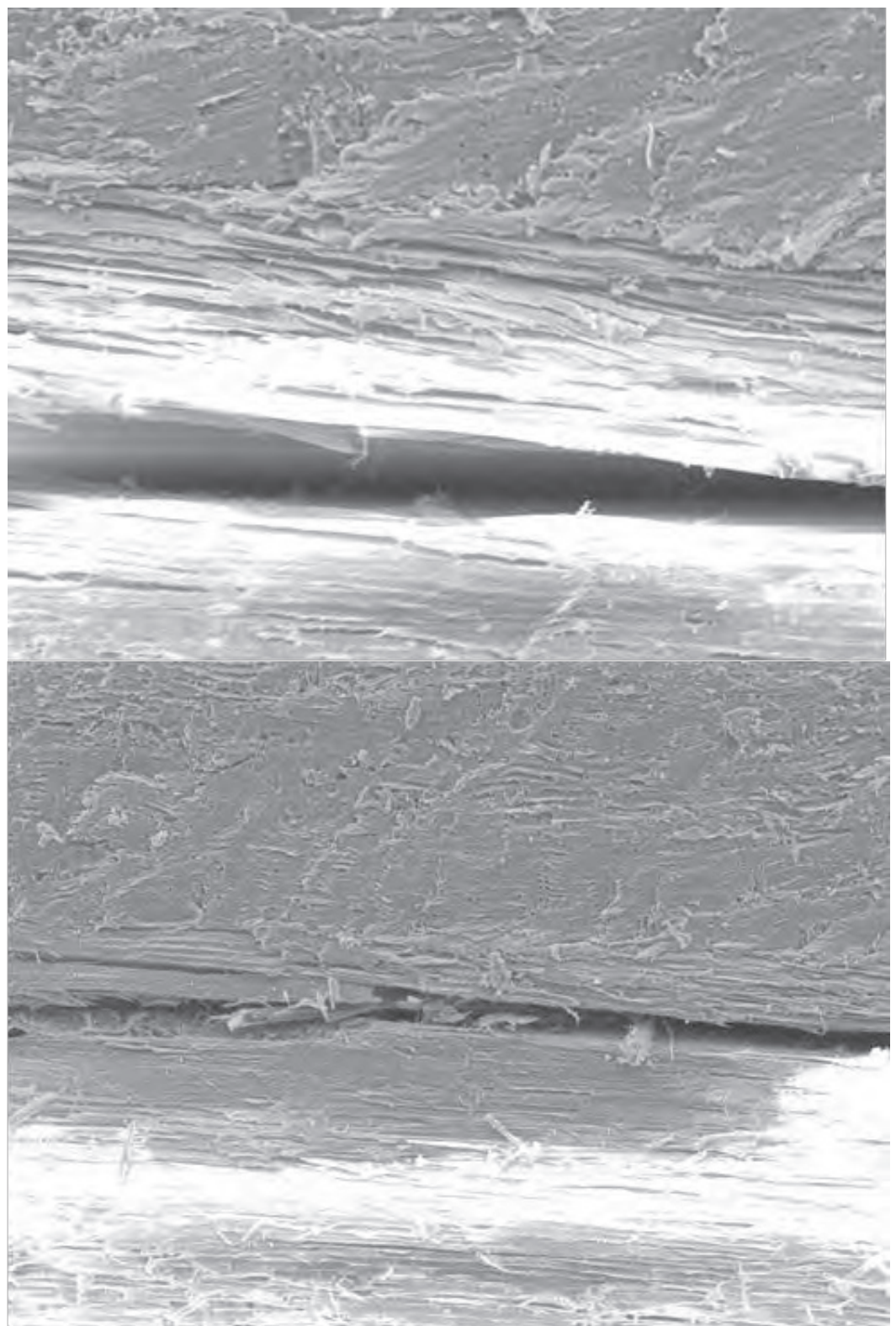

Fig. 8. Microcracks.

\section{References}

1. STO 36554501-021-2010. Wooden structures. Ultralam multilayer laminated veneer material. General technical requirements (2010)

2. C.R. Bamberg, Lateral Movement of Unbraced Wood Composite I-Joists Exposed to Dynamic Walking Loads: MSc thesis (USA, Virginia Polytechnic Institute, 2009)

3. DIN EN 14374:2004. Timber Structures - Structural Laminated Veneer Lumber Requirements (2005) 
4. GOST 33124-2014. Laminated veneer lumber. Technical conditions (M.: Standartinform, 2015)

5. DIN EN 408-2004. Timber Structures - Structural Timber and Glued Laminated Timber - Determination of Some Physical and Mechanical Properties (2004)

6. G.C. Morrissey, D.W. Dinehart, W.G. Dunn, Wood I-Joists with Excessive Web Openings: An Experimental and Analytical Investigation, Journal of Structural Engineering 655-665 (2009)

7. A.G. Chernykh, E.V. Danilov, P.S. Koval, Sh.M. Mamedov, Review of research, standardization and application of LVL beams in domestic and foreign construction practice, SPb. Bulletin of Civil Engineers 1, 100-106 (2020)

8. https: //lesprominform.ru/jarticles.html?id=5028 (date of access 24.09.2020)

9. E.K. Ashkenazi, Anisotropy of wood and wood materials (Moscow: Timber industry; 1978)

10. E. N. Serov, Development of laminated timber structures. Problems and views (SPb.: Saint-Petersburg State University of Architecture and Civil Engineering, 2015)

11. A. N. Chubinsky, V.V. Sergeevichev, Modeling the processes of gluing wood materials (Saint Petersburg: Gerda Publishing House, 2007)

12. G. Pot, L-E. Denaud, R. Collet, Numerical study of the influence of veneer lathe checks on the elastic mechanical properties of laminated veneer lumber (LVL) made of beech, Holzforschung 69(3), 337-345 (2015)

13. L. Etienne, D. Laurent, B. Florent, E. R. Marchal, Wood peeling process monitoring: $a$ comparison of signalprocessing methods to estimate veneer average lathe check frequency, Eur. J. Wood Prod. 70, 253-251 (2012) DOI 10.1007/s00107-011-05498ORIGINALS ORIGINALARBEITEN

14. W. Darmawana, D. Nandika, Y. Massijaya, A. Kabe, I. Rahayu, L. Denaud, B. Ozarska, Lathe check characteristics of fast growing sengon veneers and their effect on LVL glue-bond and bending strength, J. of Mat. Proc. Tech. 215, 181-188 (2015)

15. V.N. Volynsky, Laminated materials technology (Tutorial, Arkhangelsk, 2003)

16. GOST 28240-90. Tensile, compression and flexural testing machines. General technical requirements.

17. GOST 16483.5-73*. Wood. Methods for determining the shear strength along the fibers.

18. A.M. Borovikov, B.N. Ugolev. Handbook of wood (M. Timber industry, 1989)

19. G.S. Varankina, Formation of low-toxic laminated wood materials. Dissertation for the degree of Doctor of Technical Sciences (SPb State Forestry University, 2014)

20. O.M. Ashpina, Formaldehyde, resin, plywood, The Chemical Journal 3, 24-30 (2016) 